\title{
Improvement of Mechanical and Fatigue Properties for Aluminum Alloy 7049 By Using Nano Composites Technique
}

\author{
Alalkawi H. J. M* Ali Yousuf Khenyab** Abduljabar H. Ali*** \\ * Department of Electromechanical Engineering/ University of Technology/Baghdad/Iraq \\ *** Ministry of Higher Education and Scientific Research/Baghdad/Iraq \\ *Email: Alalkawi2012@yahoo.com \\ **Email: Al2024T4@gmail.com \\ ***Email: dr.abduljabarha@yahoo.com
}

(Received 24 January 2018; accepted 14 August 2018)

https://doi.org/10.22153/kej.2019.08.001

\begin{abstract}
The aim of present work is to improve mechanical and fatigue properties for Aluminum alloy7049 by using Nano composites technique. The $\mathrm{ZrO}_{2}$ with an average grain diameter of 30-40 nm, was selected as Nano particles, to reinforce Aluminum alloy 7049 with different percentage as, 2, 4, 6 and $7 \mathrm{w} t \%$. The Stir casting method was used to fabricate the Nano composites materials due to economical route for improvement and processing of metal matrix composites. The experimental results were shown that the adding of zirconium oxide $\left(\mathrm{ZrO}_{2}\right)$ as reinforced material leads to improve mechanical properties. The best percentage of improvement of mechanical properties of 7049 AA was with $4 \%$ wt. of $\mathrm{ZrO}_{2}$ about $\left(7.76 \% \sigma_{u}\right)$ for ultimate tensile stress UTS, $\left(9.62 \% \sigma_{y}\right)$ for yield stress YS and (9.92\%) for hardness $\mathrm{HB}$ than other of adding of 2, 6 and $7 \%$ of $\mathrm{ZrO}_{2}$. Also the results shown that the fatigue strength of 7049 AA with $4 \mathrm{w} t \% \mathrm{ZrO}_{2}$ nanoparticles is higher than that of 7049 AA under constant loading $9.86 \%$ at $10^{8}$ cycles as well as the fatigue life factor (IFLF \%) at different amplitude stress 400, 350, 300 and $250 \mathrm{MPa}$ was improvement in range $66,115,63$ and $107 \%$ respectively.
\end{abstract}

Keywords: Nanomaterial, $7049 \mathrm{AA}, \mathrm{ZrO}_{2}$, Stir casting.

\section{Introduction}

Only few machine parts are subjected to static loading and the majority of machine parts are subjected to variable loads. Experimentally, when a material is subjected to dynamic loads, it fails at a stress below the yield stress, such type of failure is known as fatigue. Fatigue may occur under constant or variable loads. Constant fatigue loading is defined as fatigue under cyclic loading with constant amplitude and a constant mean stress or load. But in service, the structures or components are subjected to variable amplitude loading, which can be a rather complex load time history [1].

Many Techniques were used to improve mechanical and fatigue properties for metal materials such as Surface cold work, shot penning and laser shock penning......etc. [2, 3 and 4]. The aim of present work is Improved mechanical and fatigue properties for Aluminum alloy7049 by Nano composites Technique. The Nano composites material was fabricated by stir casting method using Aluminum alloy7049 as a metal matrix and Nano particles of $\mathrm{ZrO}_{2}$ as a reinforced material with different weight percentage, 2,4,6 and $7 \mathrm{w} t \%$. Metal matrix composites were studied which are widely used in an industry for many applications in aerospace, automotive and others so it is request to improve mechanical and fatigue properties of metal matrix composites for use in highperformance applications.

M. Dinesh and R. Ravindran [5] Studied hardness and tensile behavior of 7075 aluminum alloy with different reinforcement by $\mathrm{Cr}$ 
nanoparticles weight as $2,3,4,5$ and $6 \mathrm{w} t \%$ and zinc nanoparticle of $1 \mathrm{w} t \%$ by air casting technique. They found the tensile stress and hardness values of the composite higher than the unreinforced alloy. The stir casting was suitable technique for manufacture of this type of composite material.

C. Kannan and R. Ramanujam [6], Studied Nano composite Al-7075 alloy for two conditions, single and hybrid for $2 \mathrm{w} t \%$ and 4 wt.\% of SiC produced through stir casting. They observed that the addition of nanoparticles with $30-50 \mathrm{~nm}$ grain size, improved the ultimate stress and hardness by $63.7 \%$ and $81.1 \%$ for single and hybrid respectively.

Divagar, and M. Vigneshwar [7] "Fabricate 7075-T651 Al- alloy with various weight percentages of $\mathrm{SiC}$ nanoparticles $5,10 \& 15 \mathrm{w} t$ $\%$ of $\mathrm{Al}_{2} \mathrm{O}_{3}$ nanoparticles as reinforcements by stir casting process. The metal matrix Nanocomposite comprising of AA7075$\mathrm{T} 651+\mathrm{SiC}-10 \%+\mathrm{Al} 2 \mathrm{O} 3-5 \%$ exhibits $12.13 \%$ higher fatigue strength than the base metal and other composites.

S.E.Shin and D. H. Bae [8] Studied fatigue behavior of aluminum alloy 2024 matrix composites reinforced with multi-walled carbon nanotubes under the tension-compression fatigue test. Tensile and fatigue strength of the Al2024 composites increases with increasing multiwalled carbon nanotubes content. Al 2024 with $4 \mathrm{vol} . \%$ multi-walled carbon nanotubes composite shows the remarkably enhanced fatigue strength of $600 \mathrm{MPa}$ at the $2.5 \times 10^{6}$ cycles and the ratio of tensile strength to fatigue strength of 0.78 . When the composite is cyclically loaded, the developed incompatibility between the matrix and the fiber induces the fiber pull-out and it acts as a bridge when the cracks propagate. Thus, as the content of multiwalled carbon nanotubes increases in the composite, the prevailing bridging behavior of multi-walled carbon nanotubes enhances the number of fatigue cycle.

Al-Alkawi H. J. M. and Ibtihal A. [9] Studied the behavior of 2024 aluminum alloy with $\mathrm{A}_{2} \mathrm{O}_{3}$ Nano composite which was fabricated by stir casting at 450 r.p.m and casting temperature of $850^{\circ} \mathrm{C}$. The experimental tests showed an improvement in the fatigue strength and life compared to the metal matrix 2024 aluminum alloy. The S-N curves were obtained and the equations of the Nano composite which described the constant S-N curves were established based on Basquin power law equation for $0.2,0.4,0.6,0.8$ and $1.0 \mathrm{w} t \%$
$\mathrm{A}_{2} \mathrm{O}_{3}$. The experimental results analysis revealed that the fatigue strength is improved by $5.3 \%$ and the fatigue life is increased by $16.02 \%$ for 2024 aluminum alloy with $0.4 \mathrm{w} t \% \quad \mathrm{~A}_{2} \mathrm{O}_{3}$ Nano composite compared to that for metal matrix.

A.P. Utkarsh Prajapati et al [10] They studied the effect of Nano $\mathrm{Al}_{2} \mathrm{O}_{3}$ on the mechanical properties of the aluminum based alloy, they concluded that the mechanical properties of aluminum based alloy can be increase by adding $\mathrm{Al}_{2} \mathrm{O}_{3}$ Nano particles into it. Also the stirring speed significantly affects the mechanical properties of the Nano-scattered castings. The speed more than $1500 \mathrm{rpm}$ causes decrease in the elasticity. The distribution of Nano alumina particles in the aluminum from 1.0 to 3.0 , the immunization particles are consistently scattered in $\mathrm{Al}$, with alumina content under $4.0 \mathrm{wt} . \%$.

AL Alkawi H. J. M. et al [11] Investigated 7075 Al-alloy metal matrix composites with different $\mathrm{w} t \%, 0.2,0.4,0.6,0.8$, and 1.0 of $\mathrm{A}_{2} \mathrm{O}_{3}$ reinforced particles of $10 \mathrm{~nm}$ in grain size, were fabricated using stir casting technique. Discuss the influence of adding $\mathrm{Al}_{2} \mathrm{O}_{3}$ particles content on the mechanical properties of the metal material composites. They concluded the nanomaterial reinforcement lead to improve the BHN hardness, ultimate strength $\sigma_{u}$ and yield stress $\sigma_{y}$. The maximum improvement in BHN hardness, $\boldsymbol{\sigma}_{\boldsymbol{u}}$ and $\boldsymbol{\sigma}_{\boldsymbol{y}}$ was observed with $0.2 \mathrm{w} t \%$. $\mathrm{A}_{2} \mathrm{O}_{3}$. While the minimum value of ductility was obtained with $0.2 \mathrm{w} t \% \mathrm{Al}_{2} \mathrm{O}_{3}$.

R. Senthilkumar et al[12] Studied the mechanical and fatigue properties for two different composite material, 90w t\% of 2014 aluminum alloy with $10 \mathrm{w} t \%$ micron size of $\mathrm{Al}_{2} \mathrm{O}_{3}$ and $90 \mathrm{w} t \%$ of 2014 aluminum alloy with $8 \mathrm{w} t \%$ micron size of $\mathrm{Al}_{2} \mathrm{O}_{3}$ and $2 \mathrm{w} t \%$ Nano size of $\mathrm{Al}_{2} \mathrm{O}_{3}$. The results show the mechanical and fatigue properties for composite 90w t\% 2014 aluminum alloy with 8wt\% micron size of $\mathrm{Al}_{2} \mathrm{O}_{3}$ and $2 \mathrm{w} t \%$ nano size of $\mathrm{Al}_{2} \mathrm{O}_{3}$ was higher than that of composite $90 \mathrm{w} t \%$ 2014 aluminum alloy with $10 \mathrm{w} t \%$ micron size of $\mathrm{Al}_{2} \mathrm{O}_{3}$ due to Nano size of $\mathrm{Al}_{2} \mathrm{O}_{3}$ reinforcement which more effectively.

Al-Alkawi et al [13] Studied 7075 Al-alloy with nanomaterial reinforced $\mathrm{AI}_{2} \mathrm{O}_{3}$ of $10 \mathrm{~nm}$ in grain size which is used different $\mathrm{w} t \%$ as, 0.2 , $0.4,0.6,0.8$ and 1.0. It was observed that the best enhancement in fatigue strength and life occurred with $0.2 \mathrm{w} t \%$ of $\mathrm{AI}_{2} \mathrm{O}_{3}$. The fatigue strength increased by $2.86 \%$ compared to the base metal alloy. The improvement may be 
coming from uniform distribution of $\mathrm{AI}_{2} \mathrm{O}_{3}$ and minimal porosity.

Hajizamani and Baharvandi [14] Used hybrid Nano composites with A356 aluminum alloy base metal taking four weight percentages $0.5,1$, 1.5 and $2 \mathrm{w} t \%$ of $\mathrm{Al}_{2} \mathrm{O}_{3}$ and $10 \%$ volume of $\mathrm{ZrO}_{2}$. The Stir casting technique was used for manufacturing the Nano composites. They observed experimentally that the mechanical and hardness increased for all the above Nano composites in an pproximately linear manner.

Ali Mazahery and Mohsen Ostadshabani [15] Study the vol.\% of alumina nanoparticles were incorporated into the A356 aluminum alloy by a mechanical stirrer. Characterization of mechanical properties revealed that the presence of nanoparticles significantly increased compressive and tensile flow stress. The presence of Nano particle $\mathrm{Al}_{2} \mathrm{O}_{3}$ reinforcement leads to significant improvement in yield strength and ultimate tensile stress while the ductility of the aluminum matrix is retained.

\section{Material and Properties}

The material that used in this work was a 7049AA supplied from round bar of $12 \mathrm{~mm}$ in diameter. The experimental of chemical and mechanical properties of 7049AA was done at State Company for Inspection and Engineering Rehabilitation in Iraq SIER, which is reported in Table-1 and Table-2 respectively.

Table 1,

Experimental and standard chemical composition of 7049 AA in w t\%

\begin{tabular}{|c|c|c|c|c|c|c|c|c|c|}
\hline Material & $\mathbf{Z n}$ & $\mathbf{T i}$ & $\mathbf{S i}$ & $\mathbf{C u}$ & $\mathbf{F e}$ & $\mathrm{Cr}$ & Mg & Mn & Al \\
\hline Standard & 0.25 max. & 0.2 & $0.8 \max$ & $3.5-4.5$ & 0.7 & 0.1 & $0.4-1$ & $0.4-$ & Balance \\
\hline experimental & 0.22 & $\begin{array}{l}\max . \\
0.08\end{array}$ & 0.15 & 3.8 & $\begin{array}{l}\max . \\
0.25\end{array}$ & $\begin{array}{l}\max . \\
0.06\end{array}$ & 0.72 & $\begin{array}{l}0.8 \\
0.57\end{array}$ & Balance \\
\hline
\end{tabular}

Table 2,

Mechanical properties of 7049AA

\begin{tabular}{lllllll}
\hline Property & $\boldsymbol{\sigma}_{\boldsymbol{u}}$ & $\boldsymbol{\sigma}_{\boldsymbol{y}}$ & $\mathbf{E}$ & $\boldsymbol{\mu}$ & $\mathbf{E I \%}$ & $\mathbf{H B}$ \\
& $\boldsymbol{M} \boldsymbol{P a}$ & $\boldsymbol{M} \boldsymbol{P a}$ & $\boldsymbol{G} \boldsymbol{P a}$ & & & \\
\hline experimental & 515 & 312 & 73 & 0.32 & 19 & 131 \\
Standard & 520 & 317 & 74 & 0.32 & 20 & 132 \\
\hline
\end{tabular}

\section{Experimental Technique of Fabricating the Nano Composites}

Stir casting method was chosen as Technique of Fabricating the Nano composites due to economical route for improvement and processing of metal matrix composites materials. The 7049 AA was selected as the matrix and $\mathrm{ZrO}_{2}$ as nano particles, as a reinforced material with different weight percentage, 2,4,6 and $7 \mathrm{w} t \%$ with an average grain diameter of 30-40 $\mathrm{nm}$. In stir casting process, the 7049 AA was first heated above its melting temperature $\left(750^{\circ} \mathrm{C}\right)$, then keep it in the semisolid condition, at the same time the $\mathrm{ZrO}_{2}$ particles was heated at the same temperature and dropped into semisolid and mixed with 450 r.p.m stirring speed for 4 minutes. The melt was then superheated above liquid temperature and poured into the mold for fabricating the specimens. The test rig which used to prepare the Nano composite material can be seen in Figure-1.

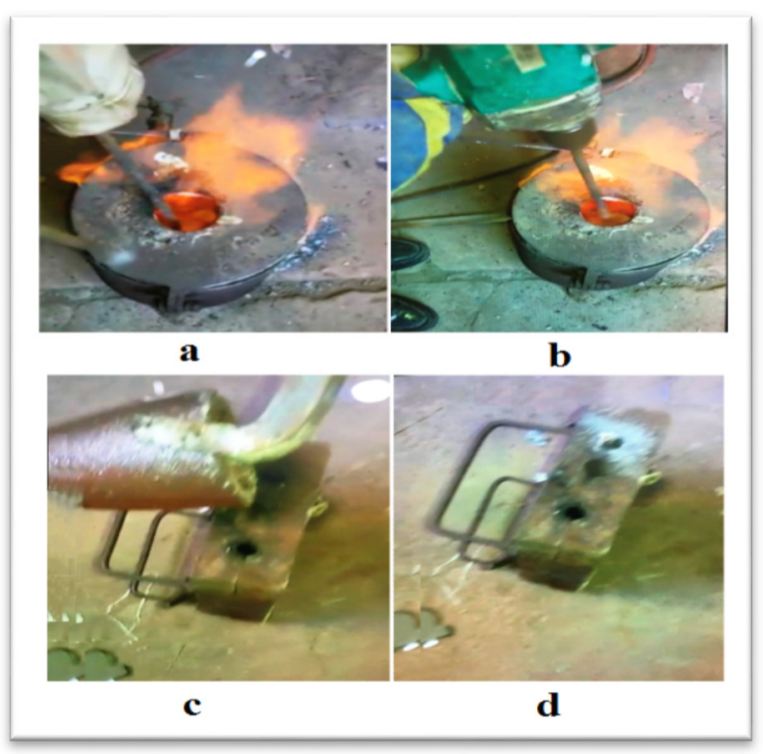

Fig. 1. Stir casting process; a: furnace Ignition and metal melting; b: move the nanoparticles with molten metal; c: the melt poured into the mold; $d$ : composites product into mold. 
The size of the composites product is $150 \mathrm{~mm}$ length and $12 \mathrm{~mm}$ in diameter. The composite product was fabricated in the rule of mixtures which can be seen in Table- 3 .

Table 3,

Nanocomposites mixture rule

\begin{tabular}{llll}
\hline $\begin{array}{l}\text { Aluminum } \\
\text { alloy }\end{array}$ & $\begin{array}{l}\mathbf{Z r O}_{2} \text { nanoparticles } \\
(\mathbf{w ~} \boldsymbol{~ \% )}\end{array}$ & $\begin{array}{l}\mathrm{ZrO}_{2} \\
(\mathbf{g ~ m})\end{array}$ & $\begin{array}{l}\text { Total } \\
\text { weight } \\
\mathbf{7 0 4 9}(\mathbf{g ~ m})\end{array}$ \\
\hline 980 & 2 & 20 & 1000 \\
960 & 4 & 40 & 1000 \\
940 & 6 & 60 & 1000 \\
930 & 7 & 70 & 1000 \\
\hline
\end{tabular}

\section{Fatigue Specimens preparation and machine Test}

Fatigue specimens were prepared according to DIN 50113, 12 specimens for 7049 AA and 24 specimens for 7049 AA with $4 \%$ wt. of $\mathrm{ZrO}_{2}$. The specimen dimensions' configuration of fatigue test was shown as in Figure-2. The silicon carbide papers were using for smooth surface of the specimen.

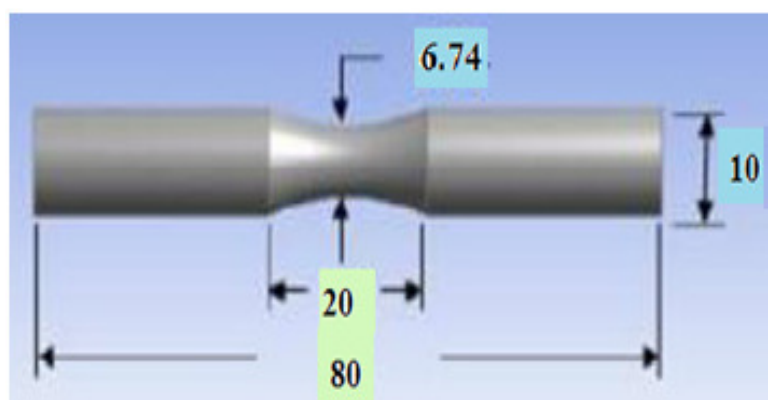

Fig. 2. The specimen dimensions in $\mathbf{m m}$ according to (DIN 50113) standard values

A rotating bending machine fatigue-testing Schenck product type as shown in figure-3 was used to implement all fatigue tests, with constant and variable amplitude stress. The fatigue specimen which is shown above has a round cross-section and is subjected to an applied load from the right side of the perpendicular to the axis of the specimen, developing a bending moment. Therefore, the surface of the specimen is under bending stress, tension and compression when it rotates.

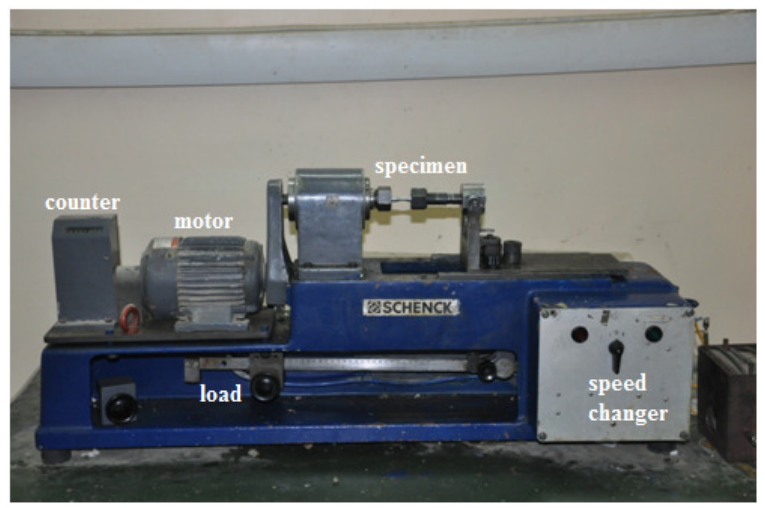

Fig. 3. Fatigue bending machine test Schenck.

\section{Results and Discussions \\ 5.1 Mechanical Properties of Composites}

The experimental of mechanical properties of 7049 AA specimens with using zirconium oxide $\left(\mathrm{ZrO}_{2}\right)$ as a reinforced material with different $\mathrm{w} t \%$ was done at State Company for inspection and engineering rehabilitation in Iraq SIER, which is reported in Table-4. The results show the adding of zirconium oxide $\mathrm{ZrO}_{2}$ as reinforced material lead to improve mechanical properties and hardness. The results show the best improvements for mechanical properties and hardness was for composite with $4 \mathrm{w} t \%$ of $\mathrm{ZrO}_{2}$ compared with that the others $\mathrm{w} t \%$ of $\mathrm{ZrO}_{2}$ as shown in Table-4 and Figure-4. The tensile stress-strain diagram up to ultimate stress for 7049AA and Nano composite with $4 \mathrm{w} t \%$ of $\mathrm{ZrO}_{2}$ was shown in Figure-5.

Table 4,

Mechanical properties result for composite 7049AA with different $w t \%$ of $\mathrm{ZrO}_{2}$.

\begin{tabular}{|c|c|c|c|c|c|c|}
\hline property & $\begin{array}{c}\sigma_{u} \\
M P a\end{array}$ & Improve. & $\begin{array}{c}\sigma_{y} \\
M P a\end{array}$ & Improve. & HB & Improve. \\
\hline $0 \%$ & 515 & ----- & 312 & ----- & 131 & ----- \\
\hline $2 \%$ & 534 & 3.689 & 320 & 2.564 & 136 & 3.816 \\
\hline $4 \%$ & 555 & 7.766 & 342 & 9.615 & 144 & 9.923 \\
\hline $6 \%$ & 540 & 4.854 & 332 & 6.410 & 138 & 5.343 \\
\hline $7 \%$ & 532 & 3.330 & 328 & 5.128 & 132 & 0.769 \\
\hline
\end{tabular}




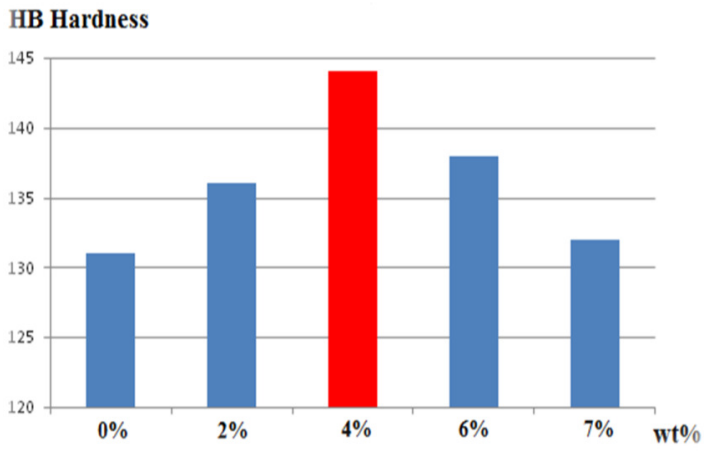

Fig. 4. Hardness (HB) result with different w $t \%$ of $\mathrm{ZrO}_{2}$.

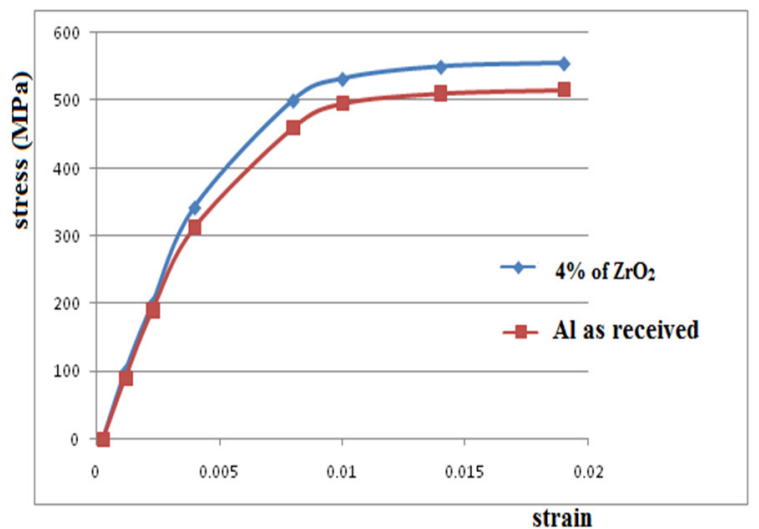

\subsection{Fatigue Test Results Under Constant Loading}

All fatigue specimens were tested under constant loading using the rotating bending machine fatigue. The fatigue Test under constant amplitude stress was for 7049AA without and with $4 \mathrm{w} t \% \mathrm{ZrO}_{2}$ only to find the improvement for fatigue properties. The S-N curves results illustrated in Table-5 at four different levels stress or amplitude stress. The average of number of cycles to failures of three specimens at each level stress is recorded. It can be observed that the effect of the addition of $4 \mathrm{w} t \%$ $\mathrm{ZrO}_{2}$ nanoparticles on fatigue behavior by seen the improvement in fatigue life through estimating the improvement fatigue life factor (IFLF \%) at different level stress by using equation-1[16].

FLIF $\%=\frac{N_{f_{c}}-N_{f_{D}}}{N_{f_{c}}} \times 100$

where $\left(N_{f D}\right)$ and $\left(N_{f c}\right)$ is number of cycle to failure for base metal or with $0 \mathrm{w} t \% \mathrm{ZrO}_{2}$ and for the composite with $4 \mathrm{w} t \% \quad \mathrm{ZrO}_{2}$ specimens respectively. The (FLIF \%) at different amplitude stress was shown in Table-5

Fig. 5. Tensile test for 7049AA and Nano composite with $4 \mathrm{w} t \%$ of $\mathrm{ZrO}_{2}$.

Table 5,

Improvement fatigue life factor (IFLF) at different amplitude stress.

\begin{tabular}{|c|c|c|c|}
\hline $\begin{array}{l}\text { Amplitude stress } \\
M P a\end{array}$ & $\begin{array}{l}\text { Average } N_{f D} \text { of } 7049 \mathrm{AA} \text { without } \\
\mathrm{ZrO}_{2}\end{array}$ & $\begin{array}{l}\text { Average } N_{f c} \text { of } 70499 \mathrm{AA} \text { with } \\
4 \mathrm{wt} \% \mathrm{ZrO}_{2}\end{array}$ & IFLF\% \\
\hline 400 & 12600 & 21000 & 66.66 \\
\hline 350 & 44800 & 96600 & 115.6 \\
\hline 300 & 190600 & 310800 & 63 \\
\hline 250 & 610800 & 1268600 & 107.7 \\
\hline
\end{tabular}

The empirical fatigue power law regression given by: $\sigma=\mathrm{a} N_{f}^{\mathrm{b}}$

where, $(\sigma)$ is the applied stress, $N_{f}$ is the number of cycles to failure and (a),(b) are the fitting parameters. The regression constants represent the fatigue trends from the model and the fatigue strength at $10^{8}$ cycles can be observed as shown in Table-6. The results show the Improvement of Fatigue strength was 9.86\%.

Table 6,

Fatigue Parameters and Fatigue Strength of AA 7049 with and without $4 \mathrm{wt} \% \mathrm{ZrO}_{2}$.

\begin{tabular}{lllll}
\hline Description & a & b & $\begin{array}{l}\text { Fatigue strength at } \\
\mathbf{1 0}^{8} \text { Cycles (MPa) }\end{array}$ & $\begin{array}{l}\text { Improvement of } \\
\text { Fatigue Strength ( \% ) }\end{array}$ \\
\hline 7049AA & 1240 & -0.1187 & 139.370 & ---- \\
7049AA with 4wt\% $\mathrm{ZrO}_{2}$ & 1283 & -0.1154 & 153.118 & 9.86 \\
\hline
\end{tabular}


The S-N curve under constant amplitude stress test for specimens 7049AA without $\mathrm{ZrO}_{2}$ or with $0 \mathrm{w} t \% \mathrm{ZrO}_{2}$ and for the composite
7049AA with $4 \mathrm{w} t \% \mathrm{ZrO}_{2}$, and the empirical power law equation it can be shown in Figure-6.

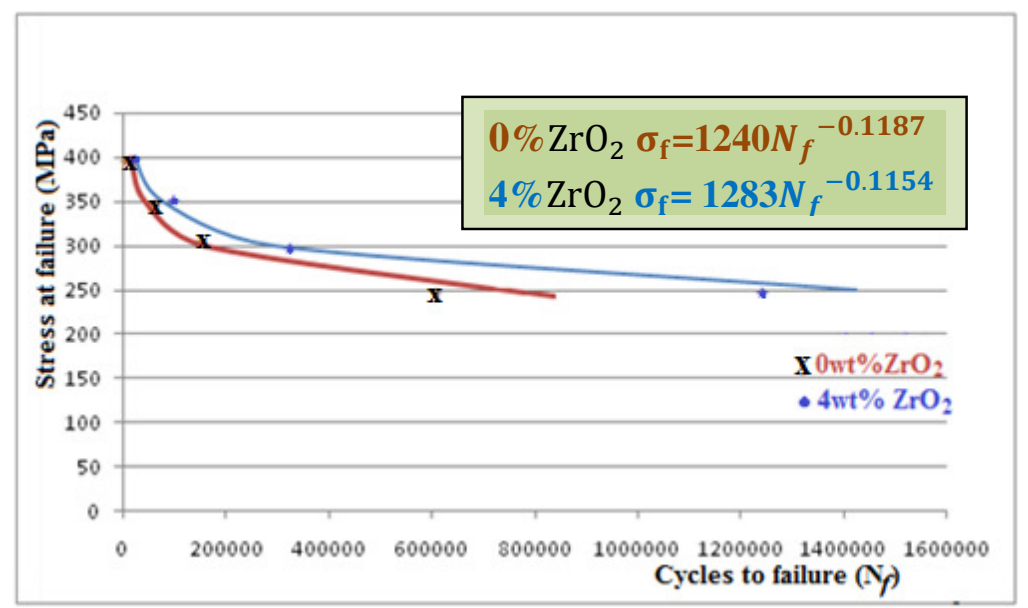

Fig. 6. S-N curves of the Nano composite with $4 \mathrm{w} t \% \mathrm{ZrO}_{2}$ compared with the base metal 7049AA with $0 \%$ $\mathrm{ZrO}_{2}$ under constant amplitude stress .

The results show the introducing $4 \%$ of $\mathrm{ZrO}_{2}$ to the7049AA lead to the higher mechanical properties, improve the fatigue life and fatigue strength. The higher mechanical properties of the $4 \mathrm{wt} \% \mathrm{ZrO}_{2}$ composite could be attributed to the fact that $\mathrm{ZrO}_{2}$ particles acts as obstacles to the motion of dislocation, the increasing in mechanical properties can be attributed to reduce grain size, leading to rise up the fatigue strength and fatigue life of composites and this results agreement with finding by Abdizadeh $\mathrm{H}$., Baghchesara M.A. [17].

\subsection{Fatigue Test Results Under Variable Loading}

Fatigue test under variable loading was done by testing specimens under variable loading for two different conditions at low to high sequences loading and high to low sequences loading by using fatigue test machine type rotary, the machine run 10000 cycles for each stress level and so on to the failure of specimen, 6 specimen for each case. Experimental fatigue test under variable loading for base metal with $0 \mathrm{wt} \% \mathrm{ZrO}_{2}$ and Nano composite $4 \mathrm{w} t \% \mathrm{ZrO}_{2}$ was recorded in Table-7. The results show improvement in fatigue life factor $33.7 \%$ and $15.8 \%$ of Nano composite with $4 \mathrm{wt} \% \quad \mathrm{ZrO}_{2}$ for both cases respectively through estimating the improvement fatigue life factor (IFLF \%) for two cases by using equation-1.

Table 7,

Experimental fatigue test under variable loading for base metal with $0 \mathrm{wt} \% \mathrm{ZrO}_{2}$ and Nano composite $4 \mathrm{w} \% \mathrm{ZrO}_{2}$

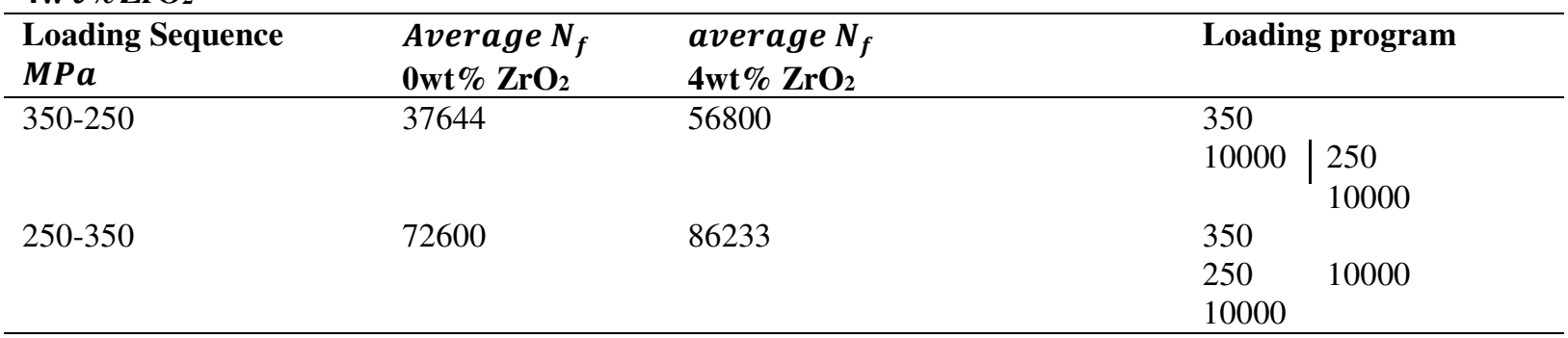




\subsection{Microstructure Analyses}

Microstructures of $7049 \mathrm{AA}$ as received and composites with the content of 4 wt. $\% \mathrm{ZrO}_{2}$, are shown in Figures-7, Dark regain represent AL matrix and bright particles represent particles of $\mathrm{ZrO}_{2}$. It can be mentioned that Nano-particle $\mathrm{ZrO}_{2}$ represents appropriate wettability with molten metal and good stability as well. It certainly should be noted that not only the wettability has an important role in the distribution of reinforcement particles in the matrix, but also, other factors such as pouring condition, stirring rate, solidification rate, etc. have profound influences on the even distribution of $\mathrm{ZrO}_{2}$ in the metal matrix, fabricated by stir casting.
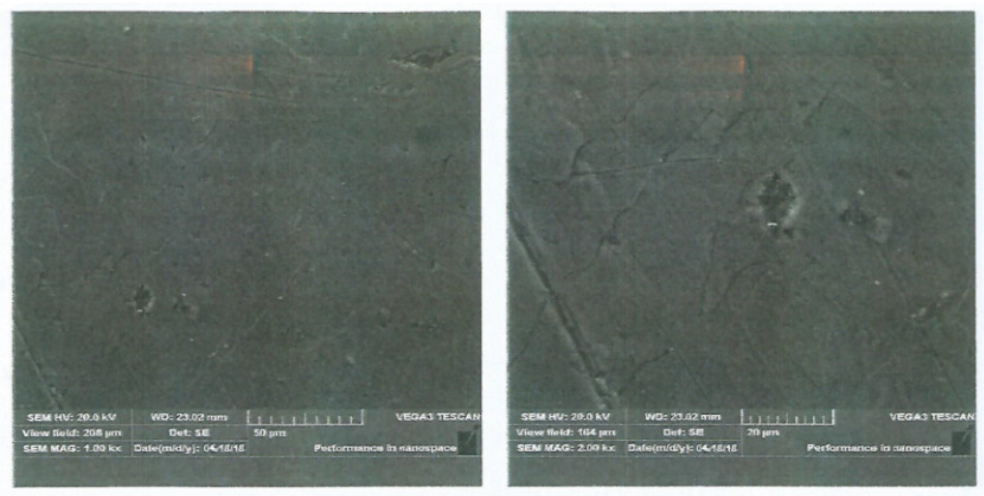

(a)
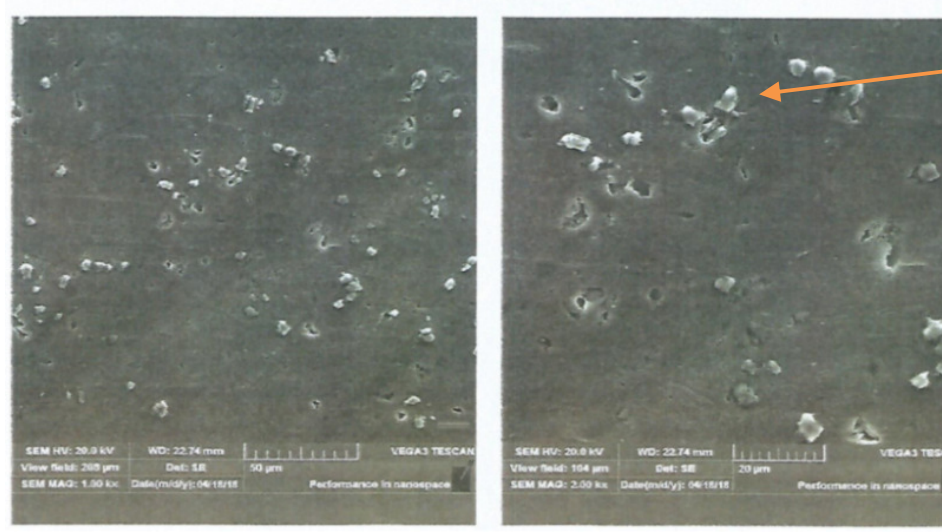

(b)

Fig. 7. (a) SEM micrograph of 7049AA as received at different magnification 50 and $20 \mu \mathrm{m}$ respectively (b)SEM micrograph of composites fabricated of 7049AA with 4wt $\mathrm{ZrO}_{2}$ at different magnification 50 and

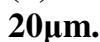

\section{Conclusions}

The results show the improvement of using different $\mathrm{w} t \%$ of zirconium oxide $\mathrm{ZrO}_{2}$ Nano particles reinforced Aluminum alloy7049 as Nano composites material on mechanical and fatigue properties. The significant findings of this investigation are as follows:

1. The mechanical properties of 7049AA specimens with zirconium oxide $\left(\mathrm{ZrO}_{2}\right)$ reinforced material lead to improving mechanical properties and hardness in different percentage according to different $\mathrm{w} t \%$ of $\mathrm{ZrO}_{2}$ reinforced 7049AA. The best improvement of mechanical properties and hardness was occurred with $4 \mathrm{w} t \%$ of $\mathrm{ZrO}_{2}$ in the rate of $\left(7.76 \sigma_{u} \%\right) \mathrm{UTS},\left(9.615 \sigma_{y} \%\right)$ YS and $(9.92 \%) \mathrm{HB}$.

2. Fatigue properties of 7049AA with $4 \mathrm{w} t \%$ $\mathrm{ZrO} 2$ are higher than that of the nonreinforced 7049AA under constant loading. Also the Fatigue life of Nano composite with $4 \mathrm{wt} \% \mathrm{ZrO} 2$ was higher than that for base metal or with $0 \mathrm{wt} \% \mathrm{ZrO} 2$ under variable loading sequence for both high to low and low to high sequence.

3. The higher mechanical properties of 7049AA with $4 \mathrm{w} t \% \quad \mathrm{ZrO} 2$ composite could be attributed to the fact that $\mathrm{ZrO} 2$ particles acts as obstacles to the motion of dislocation and 
to reduce grain size, leading to rise up the constant and cumulative fatigue life of composites.

4. The results of Fatigue test under variable loading for two different conditions at low to high sequences loading and high to low sequences loading show improvement in fatigue life factor $33.7 \%$ and $15.8 \%$ of Nano composite with $4 \mathrm{wt} \% \mathrm{ZrO} 2$ for both cases respectively.

\section{Reference}

[1] N. E. Frost, K. J. Marsh and L. P. Pook "Metal Fatigue" Clarendon Press, Oxford (1974).

[2] Koji Takahashi, Hiroko Osedo, Takaya Suzuki, Shinsaku Fukuda, "Fatigue strength improvement of an aluminum alloy with a crack-like surface defect using shot peening and cavitation peening" Engineering fracture Mechanics, vol. 193, pp. 151-161, April 2018.

[3] Abdul-Jabar H. Ali, "Improvement of Fatigue Life of AA 7075 Using Laser Shock Peening (LSP) Surface Treatment Technique", Al-TAQANI Refereed Scientific Journal, vol. 29, pp. 47-57 (2016).

[4] Dorman, M., Toparli, M. B., Smyth, N., Cini, A., Fitzpatrick, M. E. and Irving, "Effect of laser shock peening on residual stress and fatigue life of clad 2024 aluminum sheet containing scribe defects", Materials Science and Engineering: A, 548, pp. 142-151, (2012).

[5] M. Dinesh, R.Ravindran "Tensile and hardness behavior of aluminum 7075 and Zinc and Chromium metal matrix composite by Stir-Casting Route" International Archive of applied Sciences and Technology, vol. 7 , pp. 39- 46 (2016).

[6] C. Kannan, R. Ramanujam," Comparative study on the mechanical and microstructural characterisation of AA 7075 nano and hybrid nanocomposites produced by stir and squeeze casting" Contents lists available at Science Direct Journal of Advanced Research 309-319 8 (2017).

[7] S. Divagar, M. Vigneshwar, S.T. Selvamani " Impacts of Nano Particles on Fatigue Strength of Aluminum Based Metal Matrix Composites for Aerospace" Materials Today: Proceedings, vol. 3, pp. 3734-3739, (2016).

[8] S.E.Shin, D.H.Bae," Fatigue behavior of Al2024 alloy-matrix nanocomposites reinforced with multi-walled carbon nanotubes" Science Direct, Composites Part B: Engineering Volume 134, Pages 61-68, (1 February 2018).

[9] Al-Alkawi H.J. M., Ibtihal A. M., Mamoon A. A. Al- Jaafari," An Estimation Study on Fatigue Transition Life of Nanocomposites Reinforced by Al203"Arab universities union general secretary of Arab engineering colleges society, (2017).

[10] A.P. Utkarsh Prajapati, A.P. Jay H Patel, Ketul V Patel, Parthkumar P Patel, Pujan P Bhatt, Sandipkumar O Varma," Effect ofAl2O3Nano-ParticleonMechanical

Properties of Aluminum Based Alloy: A Review", IOSR Journal of Mechanical and Civil Engineering (IOSR-JMCE) e-ISSN: 2278-1684, p-ISSN: 2320-334X, Volume 13, Issue 2 Ver. II, PP 72-75, (Mar. - Apr. 2016)

[11] Al-Alkawi H.J.M., Abthal A. M., Mamoon A. A. Al- Jaafari," Mechanical Properties of 7075 Aluminum Alloy $\mathrm{Matrix} / \mathrm{Al}_{2} \mathrm{O}_{3}$, Particles Reinforced Composites" Engineering and Technology journal, (2017).

[12] R. Senthilkumar, N. Arunkumar, M. Manzoor Hussian,"Comparative Study on Low Cycle Fatigue Behaviour of Nano and Micro A1203 Reinforced AA2oI4 Particulate" Hybrid Composites Results in Physics, vol. 5, pp. 273-280 (2015).

[13] Al-Alkawi H.J.M., Ibtihal A. M., Mamoon A. A. Al- Jaafari," Fatigue life Study on 7075 Aluminum Alloy matrix / nanoparticles $\mathrm{Al}_{2} \mathrm{O}_{3}$ reinforced composite" The Iraqi Journal for mechanical and materials Engineering (2017).

[14] Hajizamani, Hamidreza Baharvandi" Fabrication and studying the mechanical properties of A356 alloy reinforced with $\mathrm{Al}_{2} \mathrm{O}_{3}-10 \%$ Vol. $\mathrm{ZrO}_{2}$ nanoparticles through stir casting" Advances in Materials Physics and Chemistry, vol. 1, pp. 26-30 (2011).

[15] Ali Mazahery1 and Mohsen Ostadshabani, "Investigation on mechanical properties of nano- $\mathrm{Al}_{2} \mathrm{O}_{3}$-reinforced aluminum matrix composites "Journal of Composite Materials 45(24) 2579-2586, (2011).

[16] Sharp P. K., Barter S. A. and Clark G., "Localized life extension specification for the F/A-18. Y470x19 pocket", Melbourne: DSTO-TN-0279, (2000).

[17] Abdizadeh H., Baghchesara M.A., "Investigation into mechanical properties and fracture behavior of A356 aluminum alloybased $\mathrm{ZrO}_{2}$ particle reinforced metal matrix composites" Mechanics of composite materials, Vol.49, No.5 (2013). 


\title{
تحسين الخصائص الميكانيكية و الكلال لسبيكة المنيوم 9 ؟ • V باستخدام تقنية المركبات النانوية المباية
}

\author{
عبدالجبار حسين علي***

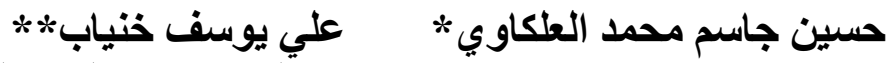

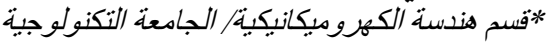

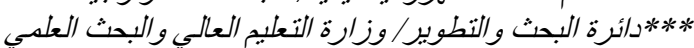 \\ * البريد الالكتروني:yahoo.com * \\ Al2024T4@gmail.com * * البريد الالكتروني: * \\ dr.abduljabarha@yahoo.com البريد الالكتروني: البكرني:
}

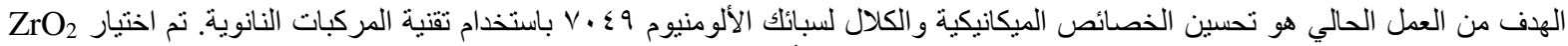

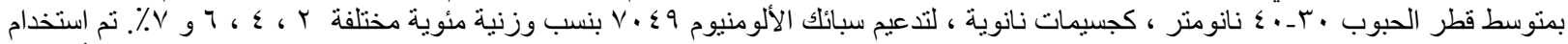

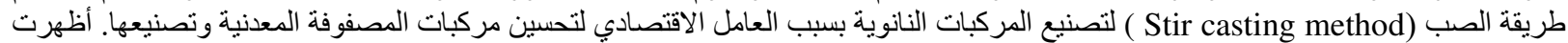

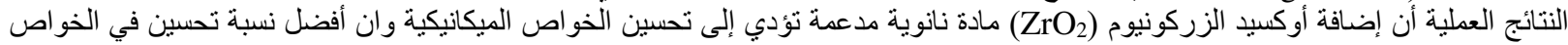

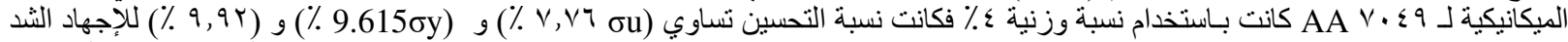

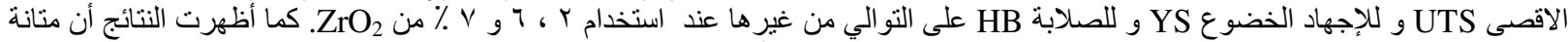

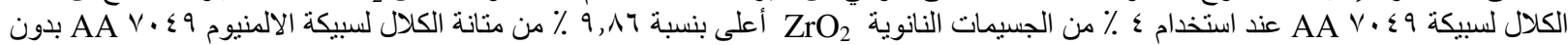

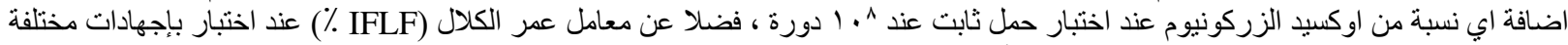

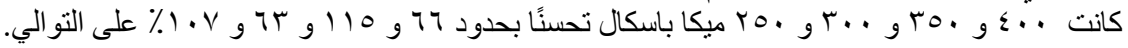

